\title{
IZGUBLJENI U JELOVNIKU: PREVODITELJSKE STRATEGIJE I MEĐUJEZIČNI UTJECAJI
}

\author{
Sandra Mardešic ${ }^{*}$ \\ Filozofski fakultet Sveučilišta u Zagrebu \\ Vanda Maržić-Sabalićc* \\ Filozofski fakultet Sveučilišta u Zagrebu
}

U gastronomiji posebno mjesto zauzimaju jelovnici, kratki tekstovi čija je kvaliteta prijevoda često predmet podsmijeha izvornih govornika. Način na koji je jelovnik preveden mnogo govori o kvaliteti i tipu restorana, dovodi ponekad do kulturoloških nerazumijevanja, a u slučaju potpuno pogrešnih prevoditeljskih rješenja može imati i posljedice po zdravlje gosta.

Cilj je ovoga rada prikazati prevoditeljske strategije na korpusu od 25 jelovnika hrvatskih restorana koji su prevedeni s hrvatskog na talijanski. Kvaliteta analiziranih prijevoda može se promatrati u rasponu od onih gotovo posve prihvatljivih i razumljivih izvornim govornicima, s manjim odstupanjima od jezične norme pa sve do neprihvatljivih i nerazumljivih. Analiza primijenjenih strategija na korpusu prijevoda jelovnika pridonosi osvještavanju primjene određenih prevoditeljskih rješenja u prijevodnoj produkciji tzv. "jednostavnih tekstova“".

Ključne riječi: jelovnici, prevoditeljske strategije, kvaliteta prijevoda

\section{UVOD}

Turizam je iznimno važna gospodarska grana u kojoj postoji velika potreba za prevođenjem najraznovrsnijih tekstova od kataloga, brošura, vodiča, natpisa (smeđa signalizacija) do internetskih stranica turističkih zajednica ili mrežnih stranica hotela, privatnih iznajmljivača ili ugostiteljskih objekata. U turističkom tekstu informacija mora biti ispravna, točno prevedena, komunikacija se odvija vrlo brzo, najčešće je neformalna i oslanja se uglavnom na digitalne medije.

Turistički tekst je stručni tekst informativnog tipa (Gotti, 1991, u Nigro, 2006: 48) pa se od prevoditelja očekuje da pri postupku prevođenja poštuje normu EN 15038 (2006: 4), kojom se definiraju zahtjevi za pružanje kvalitetnih prijevodnih usluga, a koji uključuju sljedeće procese: prevođenje, provjeru, jezičnu redakturu, stručnu redakturu, korekture i konačne verifikacije (2006: 9). Međutim, istraživanje provedeno analizom korpusa prijevoda

\footnotetext{
* smardesi@ffzg.hr

*** vmsabali@ffzg.hr
} 
službenih stranica turističkih zajednica s naše obale na talijanski ukazuje da se taj postupak ne provodi dosljedno, a uslijed čega mrežne stranice obiluju različitim vrstama pogrešaka (Mardešić i Maržić Sabalić, 2014).

Gastronomija je neizostavna i vrlo važna komponenta turističke ponude i najčešće prvi kontakt stranog gosta sa specifičnostima kulture jedne zemlje i/ili obilježja turističkog odredišta. Tipična nacionalna jela bogatstvo su svake zemlje, a nerijetko su i zaštićena nematerijalna baština. Interes za pripremom jela porastao je u proteklom desetljeću zahvaljujući utjecaju društvenih mreža i medija (npr. kulinarska natjecanja). Unatoč sve boljoj i raznovrsnijoj gastronomskoj ponudi, uočava se nedovoljna pozornost pri prevođenju jelovnika na strane jezike (Grammenidis, 2008; Begonja, 2016). O tome svjedoče i brojni blogovi i stranice na društvenim mrežama posvećene prikupljanju fotografija pogrešaka u prijevodima jelovnika diljem svijeta, a agencije za prevođenje sve češće u svojoj ponudi ističu izradu kvalitetnih prijevoda jelovnika.

Jelovnici se u pravilu ne doživljavaju kao zahtjevni tekstovi pa im se posljedično ne pridaje dovoljna važnost. Međutim, u okviru ugostiteljskoturističke djelatnosti jelovnik je najzastupljeniji tip teksta. Prema Werlichovoj tipologiji teksta, često korištenoj i u talijanističkim lingvističkim studijama (Lala, 2011: 1490-1495), jelovnici se mogu uvrstiti u informativne tekstove. Oni prenose jasnu i preciznu poruku i na sažet način opisuju jelo i način njegove pripreme prema unaprijed zadanom okviru (predjelo, glavno jelo, prilozi, desert), dakle u njima prevladava pragmatička funkcija točnog prenošenja informacije.

Međutim, valja uzeti u obzir da jelovnici „ne ispunjavaju sve kriterije tekstualnosti“ prema De Beaugrandeu i Dressleru (1981) te je zapravo riječ o "tekstovima bez kohezije“ ili tzv. kvazi-tekstovima“" (Begonja, 2016: 88-89).

Zbog toga se percipiraju kao tekstovi koji ne skrivaju poteškoće pri prevođenju i smatra se da ih svatko može prevesti ne vodeći računa o ranije opisanom postupku osiguranja kvalitete prijevoda. Grammenidis (2008) ističe da se zapravo samo iznimno radi o uslugama profesionalnih prevoditelja. Ipak, jelovnici određuju imidž ugostiteljskog objekta, a prijevod jelovnika govori u prilog kvaliteti i tipu restorana. Prijevodom autohtonih jela zadire se u tradiciju i gastronomske običaje jedne kulture koji se samo kvalitetnim prijevodom mogu približiti korisniku. Stoga bi prevoditelji trebali dobro poznavati i kulturu i običaje (ne samo u gastronomskom smislu) strane kulture kako bi mogli kvalitetno prevesti jelovnike.

\section{CILJ RADA}

Cilj je ovoga rada analiza pisane jezične produkcije na primjeru jelovnika prevedenih na talijanski jezik. Namjera je bila ukazati na učestalost pogrešaka u prijevodima jelovnika i ponuditi prijevodno rješenje za pojedine nazive 
jela. Pritom posebnu pozornost valja posvetiti autohtonim jelima koja nemaju ekvivalent u gastronomskoj ponudi drugih zemalja, a za čije je prevođenje potrebna kvalitetna izobrazba prevoditelja i visoka jezična kompetencija.

Jezik gastronomije može se smatrati jezikom struke jer je povezan sa specijaliziranom djelatnošću, ali za razliku od drugih jezika struke nije namijenjen isključivo stručnoj zajednici, (primjerice medicina, pravni tekstovi i sl.) već se odnosi na svakodnevni život i sadrži elemente općeg jezika.

\section{METODOLOGIJA I KORPUS}

Korpus obuhvaća 25 prijevoda jelovnika koji su prevedeni s hrvatskog na talijanski, a sadrže od 35 do 70 jela po jelovniku pa cijeli korpus obuhvaća oko 1250 jela. Najzastupljeniji su u korpusu prijevodi jelovnika restorana s područja Dalmacije ( $80 \%$ ), 10 \% ugostiteljskih objekata odnosi se na šire područje grada Zagreba, a s 10 \% zastupljeni su ostali dijelovi Hrvatske. Unatoč činjenici da su internetski sadržaji u turizmu općenito gotovo istisnuli ponudu u tiskanom obliku, jelovnici se rijetko objavljuju na internetu, stoga glavninu korpusa čine tiskani jelovnici (90\%), a tek manji dio preuzet je s mrežnih stranica. Isto tako valja napomenuti da većina ugostitelja nije voljna dati na uvid svoje jelovnike koji su izrađeni „po mjeri“ ugostiteljskog objekta, stoga je analizirani korpus prigodni, prikupljen fotografiranjem autoricama dostupnih jelovnika.

Premda je prema službenim podatcima Državnog zavoda za statistiku gotovo 1,2 milijuna talijanskih gostiju posjetilo Hrvatsku tijekom 2018., prijevodi jelovnika na talijanskom jeziku nisu ravnomjerno zastupljeni. Prema popisu 50 najboljih restorana za 2018. koje ocjenjuje Jutarnji list, samo osam na svojim mrežnim stranicama ima prijevode jelovnika na talijanski, a od restorana s Michelinovom preporukom za 2018., samo četiri imaju prijevode svojih menija i na talijanskom. Najveći broj prijevoda jelovnika na talijanskom nalazimo na istarskom i dalmatinskom području, a u znatno manjoj mjeri na zagrebačkom području gdje prevladavaju prijevodi na engleskom. $S$ obzirom na veliku raznolikost ponude jela, iz naše analize izostavljena su internacionalna jela, a veća je pozornost posvećena tipičnim jelima iz različitih krajeva zemlje.

U analizi prijevodnih rješenja obratila se pozornost jesu li, i u kojoj mjeri, prevoditelji uspjeli zadovoljili kriterije jasnoće, točnosti i učinka (Stolze 1999 u Pritchard, 2015: 66) na ortografskoj, morfosintaktičkoj i semantičkoj razini. Za analizu prevođenja kulturno-specifičnih elemenata primijenjena je klasifikacija postupaka za prevođenje elemenata kulture: posuđivanje ili preuzimanje, doslovan prijevod ili kalk, kulturni ekvivalent ili zamjena, objašnjenje, dodavanje, izostavljanje, neologizam i kombinacija dvaju ili više postupaka (Veselica-Majhut, 2012 u Pavlović, 2015: 73). 


\section{REZULTATI ISTRAŽIVANJA}

U analiziranom korpusu od približno 1250 riječi zabilježeno je ukupno 411 prijevodnih pogrešaka koje se kreću u rasponu od manjih odstupanja do potpuno neprihvatljivih i nerazumljivih prijevodnih rješenja.

\subsection{Analiza na ortografskoj razini}

Mnogo je primjera manjih i većih pravopisnih odstupanja $(\mathrm{N}=120)$, pri čemu je razumljivost poruke uglavnom sačuvana. Primjer manjih odstupanja $(\mathrm{N}=20)$ jest ispuštanje obaveznih dijakritičkih znakova u talijanskom jeziku (accento grave), primjerice, *specialita, *qualita, *baccala, *tiramisu, a mnogo su zastupljenija u korpusu ( $\mathrm{N}=64)$ ortografska odstupanja od pravopisne norme npr. *cotoleta, *margarita, *arosto, *spagheti, *fruti di mare, *cucinatti, *sepia, *in panato, *acciugge, *anti pasti, *cingiale koja u nekim slučajevima rezultiraju potpuno nerazumljivim rješenjima: *antara, *frmaggi, "rocula, *alla bouzara, *gaberi, *scombro, *achiugge ( $\mathrm{N}=7)$.

Odstupanja od pravopisne norme ciljnoga jezika mogu se raspoznati i u primjeni pravila pisanja malog i velikog slova $(\mathrm{N}=30)$ (npr. l'Orata, Il Pesce, Prosciutto Dalmata, Filetto di Tonno, Insalata Caprese, crema di Mascarpone, Panna Cotta, prosciutto crudo Dalmata, scaloppina alla Viennese) pri čemu poruka ostaje sasvim razumljiva, ali umanjuje se kvaliteta prijevoda. Pritom ne treba zanemariti i činjenicu da se u ovom slučaju može raditi i o tiskarskim pogreškama, ali s druge strane i da prevoditelj nije proveo postupak redakture prijevoda što ide u prilog pretpostavci da nije riječ o profesionalnim prevoditeljima.

\subsection{Analiza na morfosintaktičkoj razini}

Na morfosintaktičkoj razini zabilježene su ukupno 154 pogreške pri čemu je najzastupljeniji prijevodni postupak doslovni prijevod s hrvatskoga $(\mathrm{N}=25)$, pogreške $\mathrm{u}$ upotrebi prijedloga doslovnim prijevodom s hrvatskoga $(\mathrm{N}=36)$, gramatičke pogreške slaganja imenice i pridjeva $(\mathrm{N}=30)$, te jukstapozicija $\mathrm{s}$ ispuštanjem obveznih prijedloga $(\mathrm{N}=26)$.

U tabličnom obliku prikazano je nekoliko naziva preuzetih iz korpusa na hrvatskom i $\mathrm{u}$ talijanskom prijevodu, dok se $\mathrm{u}$ desnom stupcu nalaze predloženi prijevodi autorica. Isti način prikaza korišten je i u tablicama 2 i 3. 
Tablica 1. Analiza prijevodnih rješenja na morfosintaktičkoj razini

\begin{tabular}{|l|l|l|}
\hline $\begin{array}{l}\text { jelo u ponudi } \\
\text { (korpus) }\end{array}$ & $\begin{array}{l}\text { prijevod u jelovniku } \\
\text { (korpus) }\end{array}$ & predloženi prijevod \\
\hline blitva na dalmatinski & bietole *su dalmata & bietole alla dalmata \\
\hline $\begin{array}{l}\text { sir iz ulja } \\
\text { sir u ulju }\end{array}$ & formaggio *da olio & formaggio sott'olio \\
\hline lignje na žaru & calamari *sulla brace & calamari alla brace \\
\hline dalmatinski pršut & prosciutto *dalmatino & prosciutto crudo dalmata \\
\hline paški sir & formaggio *paghesano & pecorino dell'isola di Pag \\
\hline zagrebački odrezak & *Zagabria bistecca & $\begin{array}{l}\text { scaloppina /fettina alla zagabrese impanata e } \\
\text { farcita con prosciutto e formaggio } \\
\text { Cordon bleu }\end{array}$ \\
\hline sezonska salata & *stagione insalata & insalata di stagione \\
\hline salata s mozzarellom & *mozzarella insalata & insalata con mozzarella \\
\hline dječji steak & *bambini bistecca & bistecca/steak per bambini \\
\hline $\begin{array}{l}\text { domaće lignje } \\
\text { domaći sir } \\
\text { domaći krumpir } \\
\text { domaći kruh }\end{array}$ & $\begin{array}{l}\text { calamari *domestici } \\
\text { formaggio *domestico }\end{array}$ & $\begin{array}{l}\text { calamari nostrani/dell'Adriatico } \\
\text { formaggio tipico locale/tradizionale/del posto } \\
\text { panovelle } \\
\text { pane casalingo nostrane/locali } \\
\text { pane casereccio/casareccio }\end{array}$ \\
\hline dnevni meni & *menu quotidiano & menù del giorno \\
\hline dnevno varivo & *giorno stufato & minestrone/zuppa del giorno \\
\hline
\end{tabular}

Većina pogrešaka u prijevodima jelovnika na ovoj razini proizlazi iz primjene postupka doslovnog prijevoda, a najčešće nedoumice prevoditelja odnose se na korištenje imenica, prijedloga i pridjeva u ciljnom jeziku.

Autohtono jelo dalmatinske gastronomije blitva na dalmatinski najčešće je prevedeno kao *bietole su dalmata pri čemu se izravno prenosi značenje hrvatskog prijedloga na kao su umjesto talijanskoga prijedloga $a$ s određenim članom (alla). Istovjetan slučaj zabilježen je s jelom lignje na žaru (calamari * sulla brace). Kod sira u ulju/sira iz ulja pogrešna upotreba prijedloga (formaggio *da olio) rezultira porukom koja je uglavnom razumljiva govorniku talijanskoga jezika (kao i u prethodnim primjerima s pogrešnim prijedlozima), ali izostaje semantičko značenje kojim bi se označio način pripreme jela (alla brace) i čuvanja namirnica (sott'olio).

U primjerima paški sir, dalmatinski pršut i zagrebački odrezak dolazi do izražaja učestala upotreba toponima $u$ nazivima jela. $U$ primjerima naziva jela u kojima je toponim izražen pridjevom na hrvatskom jeziku prevoditelj ni u jednom slučaju nije pronašao prikladno rješenje. Za dva karakteristična predjela u našim jelovnicima, paški sir i dalmatinski pršut, odabran je $\mathrm{u}$ prvom slučaju nepostojeći pridjev paghesano, a u drugom se slučaju koristi neadekvatni pridjev dalmatino premda u talijanskom postoji točan ekvivalent. Naime, jednojezični rječnik talijanskoga jezika Treccani on line navodi upotrebu pridjeva dalmatino, ali se u kulinarskom kontekstu smatra prikladnijom upotreba pridjeva dalmata. U slučajevima prijevoda naziva paški sir i dalmatinski pršut autorice predlažu detaljniji opis i posuđivanje u skladu 
s postupcima prevođenja kulturno-specifičnih elemenata kako bi korisnik odmah prepoznao jedinstvenost autohtonog proizvoda. Tako bi za paški sir prikladan prijevod glasio pecorino dell'isola di Pag pri čemu se posuđivanjem iz ciljnoga jezika ukazuje (pecorino) da se radi o ovčjem siru, dok bi za dalmatinski pršut prikladna inačica sadržavala i naznaku vrste pršuta (prosciutto crudo dalmata) koja bi govorniku talijanskog jezika odmah razjasnila da se ne radi o šunki za koju Talijani rabe naziv prosciutto cotto, već o soljenom i dimljenom karakterističnom proizvodu Dalmacije.

Za proizvode koji nose zaštićenu oznaku zemljopisnog podrijetla, kao što je slučaj s dalmatinskim pršutom i paškim sirom, autorice predlažu prijevodni postupak posuđivanja s opisnim prijevodom. Premda opisni prijevod ponekad zahtijeva više prostora u ograničenom grafičkom uređenju jelovnika, autorice smatraju da je u ovakvim slučajevima taj prijevodni postupak opravdan jer donosi potpunu informaciju.

U primjeru zagrebačkog odreska prijevodna se pogreška odnosi na prijevod toponima preuzetog $\mathrm{u}$ obliku vlastite imenice $\left({ }^{*}\right.$ Zagabria bistecca), umjesto pridjeva koji bi bio prikladniji (zagabrese). I u ovom se slučaju predlaže uz naziv jela bistecca zagrabese dodatak opisnog prijevoda scaloppinalfettina impanata farcita con prosciutto e formaggio, a može se primijeniti i kraća internacionalna inačica Cordon bleu koja bi talijanskom govorniku bila u potpunosti razumljiva.

Doslovan prijevod primijenjen je i u slučaju naziva sezonska salata i dječji steak ( ${ }^{*}$ stagione insalata, ${ }^{*}$ bambini steak) primjenom jukstapozicije, odnosno izostavljanjem prijedloga između imenice i pridjeva. Isti postupak zabilježen je i u slučaju sira iz Krasnog, prevedenog kao * Krasno formaggio pri čemu primatelj poruke dobiva samo polovičnu informaciju o jelu, a ne i o autohtonosti i posebnosti proizvoda.

Hrvatski ugostitelji često naglašavaju domaće podrijetlo namirnica $s$ namjerom isticanja kvalitete, dok se u ponudi jela u Italiji vrlo rijetko koristi pridjev domaći za opis podrijetla namirnice. Pridjev domaći gotovo je uvijek doslovno preveden $\mathrm{s}{ }^{*}$ domestico, pridjevom kojim se označava pripadnost domu, obiteljskoj atmosferi, ali koji nije prikladan za opis podrijetla gastronomskog proizvoda. U slučaju mekušaca autorice predlažu postupak adaptacije, inačicu calamari nostrani ili dell'Adriatico (iz Jadranskog mora), za domaći sir postoji nekoliko prijevodnih varijanti poput formaggio tipico locale, formaggio tradizionale, formaggio del posto. Bila bi prikladna i upotreba pridjeva nostrano, ali to je ujedno i zaštićeni naziv vrste sira u nekoliko talijanskih regija (Nostrano Valtrompia, Nostrano Alpe Vaia itd.) pa tu varijantu valja izbjegavati. Za domaći krumpir ponuđen je semantički neadekvatan ekvivalent u ciljnom jeziku koji označava mladi krumpir (patate novelle). U ciljnom su jeziku moguće varijante patate nostrane, patate locali. Posljednji primjer iz korpusa s pridjevom domaći odnosi se na domaći kruh doslovno preveden kao pane casalingo. Ta je varijanta jezično prihvatljiva i može se koristiti, ali u ciljnom jeziku učestala 
je upotreba i drugog pridjeva koji označava pripremu kruha na domaći način (pane casareccio ili casereccio). U prijevodu * menu giornaliero korišten je ispravan ekvivalent pridjeva dnevni, ali vidljivo je nepoznavanje termina koji se u ciljnom jeziku rabi u gastronomiji za označavanje ponude dana na meniju (menu del giorno), dok je prijevod * giorno stufato za dneono varivo u potpunosti nerazumljiv.

\subsection{Analiza na semantičkoj razini}

Na semantičkoj razini uz dosad prikazane primjere prijevodne strategije doslovnog prijevoda s hrvatskoga ( $N=25)$ (v. tablicu 2), zabilježene su i strategije posuđivanja iz drugih jezika $(\mathrm{N}=46)$ u slučajevima u kojima postoji uglavnom potpuni ekvivalent $\mathrm{u}$ talijanskom (npr. mangel con patate, cherry pomodoro, octopus insalata, bacon domestico, lobster). U nekoliko slučajeva $(\mathrm{N}=11)$ imamo i pogrešne leksikalizacije hrvatskih ili neadekvatne adaptacije talijanskih riječi (npr. " ramstecca, "patate rostite, * conquiglie, ${ }^{*}$ sardelline), a primjenjuje se čak i dijalekt kao ekvivalent - pomidor. Ipak, u semantičkom smislu, valja naglasiti da se najveći broj pogrešaka odnosi na uopćavanje značenja $(\mathrm{N}=81)$, tj. semantička proširenja izvornih značenja talijanskih riječi pri prijevodu čime nesnalaženje prevoditelja postaje još izraženije jer se često postiže komičan efekt pa prijevod postaje katkada neprihvatljiv i nerazumljiv izvornom govorniku.

Tablica 2. Analiza prijevodnih rješenja na semantičkoj razini

\begin{tabular}{|l|l|l|}
\hline jelo u ponudi (korpus) & prijevod u jelovniku (korpus) & predloženi prijevod \\
\hline file kovača & *file di fabbro filetto & filetto di pesce San Pietro \\
\hline gulaš od veprovine & gulash di *selvatica di maiale & spezzatino/gulasch di cinghiale \\
\hline punjena paprika & *paprica riempita & peperoni ripieni/farciti \\
\hline prilog & $\begin{array}{l}\text { *appendice } \\
\text { *allegato }\end{array}$ & contorno \\
\hline salata od hobotnice & insalata di *polipo, di *piovra & insalata di polpo \\
\hline voćna salata & *insalata di frutta & macedonia \\
\hline
\end{tabular}

Komičan efekt postignut je u dva primjera doslovnog prijevoda za riblje jelo file kovača i gulaš od veprovine. Specijalitet od ribe kovača pretvoren je u majstora kovača (fabbro), dok je gulaš od veprovine preveden na način da je korišten doslovan prijevod sintagme *selvatica di maiale za divlju svinju, nepostojeći termin u ciljnom jeziku.

U primjeru doslovnog prijevoda jela *paprica riempita za punjenu papriku dolazi do prijenosa krivog značenja jer govorniku ciljnog jezika prvi dio izraza označava začin jelu (paprika), umjesto povrtne kulture peperone, a pridjev riempito predstavlja semantičko proširenje značenja glagola riempire, dok se u gastronomiji koristi ripieno ili farcito.

Iz prijevoda u ovoj kategoriji vidljivo je i semantičko proširenje značenja u primjeru salata od hobotnice koja je prevedena kao *insalata di polipo ili 
* insalata di piovra umjesto ispravnog prijevoda insalata di polpo. Premda imenice polpo i piovra (Octopus vulgaris Cuvier) označavaju istu vrstu, potonja se upotrebljava i u prenesenom značenju označavajući mafijašku zločinačku organizaciju koja širi posvuda svoje „pipke“. Naziv polipo (žarnjak) ne treba koristiti s obzirom na to da se radi o nejestivoj morskoj vrsti.

U slučaju primjera prijevoda naziva prilog primijenjen je doslovan prijevod u kojem se pogreška temelji na polisemiji leksema u izvornom jeziku. Prevoditelj nije prepoznao polisemiju i prenio je u ciljni jezik neadekvatnu inačicu (appendice je prilog znanstvenom članku/knjizi, a allegato je prilog $\mathrm{u}$ korespondenciji), koja ne samo što ne ispunjava informativnu funkciju već izaziva podsmijeh. Naglašavamo da je primjer takvog neadekvatnog semantičkog proširenja jedan od najčešćih na mnogim blogovima, mrežnim stranicama i društvenim mrežama posvećenim pogreškama pri prevođenju jelovnika i na drugim jezicima npr. appendix, contributions.

Voćna salata prevedena kao *insalata di frutta doslovan je prijevod $\mathrm{s}$ hrvatskoga pri čemu je vidljiv manjak enciklopedijskog znanja u talijanskom, odnosno da je potrebna upotreba ekvivalenta macedonia iz čega je jasno da su prevoditelji izostavili fazu analize prijevodnih problema i revizije prijevoda.

\subsubsection{Analiza prijevodnih rješenja kulturno specifičnih elemenata}

U nastavku semantičke analize osvrnut ćemo se na prijevode kulturnospecifičnih elemenata $(\mathrm{N}=25)$ pri čijem je prevođenju došlo do primjene različitih prijevodnih postupaka: doslovnog prijevoda, leksikalizacije pojma iz izvornog jezika i ispuštanja u smislu neprevođenja. Postupci i prijevodni ishodi koji su njima dobiveni zrcale činjenicu da je i prevoditeljima iznimno visokih jezičnih kompetencija najteže prevoditi kulturno-specifične elemente za koje u ciljnoj kulturi nema postojećih ekvivalenata.

Analizirani korpus obiluje nepreciznim prijevodima u kojima prevoditelj nije primijenio prijevodne postupke kako bi korisniku na najbolji mogući način približio kulturnu referenciju i prikazao specifičnost autohtonog jela, odnosno nije ispunjena pragmatička funkcija teksta. U sljedećoj se tablici navode loša prevoditeljska rješenja i predlažu prikladni prijevodi i približni ekvivalenti pojedinih specijaliteta razumljivih izvornom govorniku. 
Tablica 3. Analiza prijevodnih rješenja na semantičkoj razini autohtonih jela

\begin{tabular}{|l|l|l|}
\hline jelo u ponudi (korpus) & $\begin{array}{l}\text { prijevod u jelovniku } \\
\text { (korpus) }\end{array}$ & predloženi prijevod \\
\hline sarma & *cavolo rotoli & $\begin{array}{l}\text { involtini di crauti con ripieno di } \\
\text { carne macinata }\end{array}$ \\
\hline zapečeni zagorski štrukli & *al forno Zagorje štrukli & $\begin{array}{l}\text { fagottini ripieni al formaggio fresco } \\
\text { gratinati al forno tipici dello Zagorje }\end{array}$ \\
\hline $\begin{array}{l}\text { dalmatinska rožata } \\
\text { dalmatinska rozata/ } \\
\text { rozada }\end{array}$ & *rosata dalmata & crèm caramel alla dalmata \\
\hline dalmatinska pašticada & *pasticciada dalmata & $\begin{array}{l}\text { stracotto di manzo con verdure alla } \\
\text { dalmata }\end{array}$ \\
\hline svinjetina pod pekom & *maiale di sotto la cenere & $\begin{array}{l}\text { arrosto di maiale alla "peka" } \\
\text { arrosto di maiale sotto il coppo }\end{array}$ \\
\hline škampi na buzaru & *scampi a bouzara & scampi alla busara \\
\hline
\end{tabular}

U gotovo svim navedenim primjerima prevoditelj nije uspio prenijeti posebnost kulturno-specifičnih elementa već je doslovnim prijevodima ili maštovitim opisnim prijevodom onemogućio korisniku razumijevanje tipičnih autohtonih jela. U prijevodu sarme prevoditelj je primijenio ispravan postupak opisnog prijevoda, ali nedovoljnim poznavanjem stručnih naziva u ciljnoj kulturi proizveo je nerazumljivu i duhovitu kombinaciju *cavolo rotoli pa stoga autorice predlažu širi i potpuniji opisni prijevodni postupak.

$\mathrm{Za}$ tri autohtona jela (zapečene zagorske štrukle, dalmatinsku rožatu i dalmatinsku pašticadu) prevoditelj se odlučio za preuzimanje u prvom primjeru i za leksikalizaciju pojma iz izvornog jezika u ciljni jezik u preostala dva slučaja. Ispravan postupak za prijevod prvog pojma nije proizveo željeni efekt jer korisniku i dalje nije poznato o kakvom je jelu riječ, a izraze ${ }^{*}$ rosata i *pasticciada ne može prepoznati jer nemaju ekvivalent u ciljnom jeziku. Ponuđena rješenja ispravka idu u smjeru preuzimanja i opisnog prijevoda za štrukle (zagorski štrukli - fagottini ripieni al formaggio fresco gratinati al forno), i kombinacije postupka preuzimanja uz primjenu kulturnog ekvivalenta za rožatu (rožata - crèm caramel alla dalmata) i pašticadu (pašticada - stracotto di manzo con verdure alla dalmata).

Priprema jela pod pekom uobičajen je postupak u Istri i Dalmaciji koji korisnici ciljnog jezika već prepoznaju kao karakterističan način pripremanja namirnica u tim dijelovima Hrvatske. Iz tog razloga kao jedno od mogućih rješenja predlaže se preuzimanje iz izvornog jezika (alla „peka“). Alternativa je tom rješenju i u potreba ekvivalenta iz ciljnogjezika (sotto il coppo) koji je, premda usko povezan s ovim načinom pripreme jela u regiji Abruzzo, ipak razumljiv svim korisnicima ciljnog jezika. Rješenje koje je ponudio prevoditelj (di sotto la cenere) samo je djelomično prihvatljivo zbog pogrešne uporabe prijedloga di; $\mathrm{u}$ ciljnoj kulturi poznata je priprema jela u kojoj se namirnice, umotane u foliju, prekrivaju pepelom (cottura sotta la cenere, cottura sotto la brace), ali s obzirom na to da nije riječ o ekvivalentu, autorice ne predlažu to rješenje. 
U sljedećoj tablici prikazani su primjeri dobre prakse iz korpusa $\mathrm{u}$ kojima je primijenjen postupak preuzimanja uz opisni prijevod i fonetsku adaptaciju talijanskom (cevapcici).

Tablica 4. Analiza ispravnih prijevodnih rješenja kulturno specifičnih elemenata

\begin{tabular}{|l|l|}
\hline fuži s tartufima & pasta fresca tradizionale istriana ai tartufi \\
\hline slavonski kulen & salame piccante della Slavonia \\
\hline ajvar & salsa piccante a base di peperoni rossi \\
\hline dalmatinska pržolica & $\begin{array}{l}\text { costoletta di manzo disossata alla dalmata (servita con verdure, patate e } \\
\text { salsa di aglio) }\end{array}$ \\
\hline purica s mlincima & $\begin{array}{l}\text { arrosto di tacchino con contorno di mlinci - straccetti/maltagliati di pasta } \\
\text { secca }\end{array}$ \\
\hline kajmak & formaggio spalmabile a base di burro e panna \\
\hline čevapćići/ cevapcici & bastoncini di carne macinata \\
\hline
\end{tabular}

\section{ZAKLJUČAK}

Nakon provedene analize može se zaključiti da jezična razina jelovnika prevedenih na talijanski nije zadovoljavajuća i da u većini slučajeva jelovnici nisu zadovoljili svoju informativnu funkciju, a kvaliteta prijevoda dokazuje da u velikom broju slučajeva nisu zadovoljeni kriteriji jasnoće, točnosti i učinka (Stolze 1999, u Pritchard, 2015:66). Isto tako zaključuje se da nisu uzete u obzir norme i koraci koje propisuje EN 15038 (2006: 9), analiza prijevodnih problema, revizija i korektura. Najčešći su prijevodni postupci doslovan prijevod i preuzimanje iz ciljnog jezika s pogrešnim semantičkim proširenjima. Pri prijevodu autohtonih jela primjenjuje se postupak leksikalizacije kojim se stvaraju nazivi nepoznati primatelju poruke. Rezultati ove analize upućuju na to da je pri prijevodu kulturno-specifičnih elemenata preuzimanje izvornog naziva uz opisni prijevod bolje prevoditeljsko rješenje.

Zaključak je autorica da se prijevodu jelovnika ne pristupa dovoljno stručno jer prevladava mišljenje da jelovnik može prevesti i nestručna osoba s obzirom na to da je riječ o općerazumljivom i vrlo kratkom tekstu. Iz korpusa se može zaključiti da je u velikom broju slučajeva primijenjeno automatsko prevođenje (Google translate), bez naknadne redakture. Pogrešan prijevod može imati višestruke negativne učinke, od lošeg marketinga za ugostiteljski objekt do mogućih posljedica po zdravlje gosta.

Na velikim tržištima na kojimaje moguća uska specijalizacija prevoditelja sve se više profiliraju stručni prevoditelji za kulinarstvo i gastronomiju koji svojim iskustvom svjedoče o zahtjevnosti prevođenja tekstova u gastronomiji. $\mathrm{Na}$ hrvatskom tržištu zasada još ne postoji tako uska specijalizacija prevoditelja, ali provedena analiza potvrđuje uvjerenje autorica da se prijevod jelovnika mora povjeriti stručnoj osobi čije je poznavanje gastronomskog jezika struke, ali i ciljne kulture dovoljno dobro za uočavanje gastronomskih 
specifičnosti čime se osigurava kvaliteta prijevoda. Iz iskustava tijekom prikupljanja korpusa proizlazi da je korisno ugostiteljima ponuditi bolja prijevodna rješenja u ciljnom jeziku jer je dobronamjerna primjedba uvijek dobro prihvaćena.

Podizanje razine kvalitete prijevoda moguće je projektima suradnje neofiloloških studija i voditelja ugostiteljskih objekata, a korisno je također promišljati o izradi baze podataka i/ili on-line glosara s višejezičnim prijedlozima prijevoda kako bi se udrugama ugostitelja i prevoditeljima ponudila prihvatljiva rješenja ponajprije tipičnih i autohtonih jela.

\section{LITERATURA}

Begonja, H. (2016) Prevođenje hrvatskih kulturema na njemački jezik na primjeru gastronomije grada Zadra. Doktorski rad. Zagreb: Sveučilište u Zagrebu.

De Beaugrande, R. i Dressler, W. (1981) Introduction to Text Linguistics. London i New York: Longman.

Grammenidis, S.P. (2008) Mediating Culinary Culture: the Case of Greek Restaurants Menus. Across Languages and Culures 9 (2), 219-233.

Europski odbor za nominalizaciju (2006) Europska norma EN 15038.

Lala, L. (2011) Tipi di testo. U Enciclopedia dell'Italiano. Roma: Istituto della Enciclopedia Italiana, 1490-1495.

Mardešić, S. i Maržić Sabalić, V. (2014) Linguaggio settoriale - uso dell'italiano nel settore turistico in Croazia. U Peša Matracki, I., Ljubičić, M., Kovačić, V. i Filipin, N. (ur.) Zbornik Međunarodnoga znanstvenog skupa u spomen na prof. dr. sc. Žarka Muljačića (1922. - 2009.), izdanje niza SRAZA. Zagreb: FF press, 457-464.

Nigro, M. G. (2006) Il linguaggio specialistico del turismo. Aspetti storici, teorici e traduttivi. Roma: Aranace.

Pavlović, N. (2015) Uvod u teorije prevođenja. Zagreb: Leykam international.

Pritchard, B. (2015) O jeziku struke i stručnom prevođenju. U Stojić, A., Brala-Vukanović, M. i Matešić, M. (ur.) Priručnik za prevoditelje. Rijeka: Filozofski fakultet, Sveučilište u Rijeci, $203-255$.

\section{LOST IN THE MENU - TRANSLATION STRATEGIES AND INTERLINGUAL INFLUENCE}

In gastronomy menus play a special role and although the quality of translation is often a subject of sneer among native speakers, it still says a lot about the quality and type of the restaurant, leads to cultural misunderstandings and in cases of completely wrong translations, it may have consequences to the health of the guest.

The aim of this paper is to present translation strategies on the sample of 25 set menus translated from Croatian to Italian. The quality of translations of this type of text can be seen as a continuum, from those almost entirely acceptable to native speakers, with minor deviations from language norms to unacceptable and unreasonable. The analysis of the applied strategies on the menu translations contributes to a better awareness of the use of certain translation solutions in the translation production of the so-called "simple texts".

Keywords: menu, translation strategies, quality of translation 